\title{
Research on Traffic Accessibility and Transportation Integration Level of Chang-Zhu-Tan City Group in China
}

\section{Chaokui Li, Qinlan Zhou, Kaisen Ma*, Jun Fang, Wentao Yang}

National-Local Joint Engineering Laboratory of GEO-Spatial Information Technology, Hunan University of Science and Technology, Xiangtan, China

Email: chkl_hn@163.com, *makaisen@qq.com

How to cite this paper: Li, C.K., Zhou, Q.L., Ma, K.S., Fang, J. and Yang, W.T. (2019) Research on Traffic Accessibility and Transportation Integration Level of Chang-Zhu-Tan City Group in China. Journal of Geographic Information System, 11, 715-726.

https://doi.org/10.4236/jgis.2019.116043

Received: November 24, 2019

Accepted: December 20, 2019

Published: December 23, 2019

Copyright $\odot 2019$ by author(s) and Scientific Research Publishing Inc. This work is licensed under the Creative Commons Attribution International License (CC BY 4.0).

http://creativecommons.org/licenses/by/4.0/

(c) (i) Open Access

\begin{abstract}
Aiming at the problem of lack of data model to analyze the level of transportation integration, the paper taking Changsha-Zhuzhou-Xiangtan City Group of China as the research object, based on the Gravity measurement model, transportation comprehensive distance model, weighted road density model, analysis of Changsha-Zhuzhou-Xiangtan City Group accessibility and transportation integration level. A new method to measure the level of traffic integration is proposed and verified by the road network data and socio-economic data of Changsha-Zhuzhou-Xiangtan City Group. The results show that: Changsha-Zhuzhou-Xiangtan City Group traffic accessibility was "point to surface" shape distribution, taking the core region of Changsha as the optimal, Xiangtan, Zhuzhou, Changsha County next, in remote Yanling County, Chaling county has the lowest accessibility; the correlation between traffic network connection degree and economic connection degree reached 0.871, indicating that the transportation integration level of urban agglomerations has a high degree of fit with the level of economic integration. The research results on the one hand for the Chang-Zhuzhou-Xiangtan urban agglomeration traffic present situation to make an annotation; on the other hand, that provide a reference for further optimization of Changsha-Zhuzhou-Xiangtan urban agglomeration traffic planning.
\end{abstract}

\section{Keywords}

Gravity Measurement Model, Accessibility, Road Network Density, Traffic Integration, Changsha-Zhuzhou-Xiangtan City Group 


\section{Introduction}

The level of traffic development is an important quota of the development of urban agglomeration. Traffic plays an important role in promoting the economic development of urban agglomeration. Traffic accessibility and transportation integration level are important embodiment of traffic development.

Hansen [1] first put forward the concept of accessibility in 1959, and considered that accessibility is the chance of interaction between nodes in traffic networks. Through the study of traffic and urban formation, Philipp Rode et al. [2] discussed the direct influence of urban accessibility for path on urban development. Li Tao [3] and other domestic scholars have studied the influence of inter-city railway on the regional tourism spatial pattern, and concluded that the tourism accessibility under the influence of inter-city railway has the characteristics of "corridor effect" and "tunnel effect". The spatial pattern distributes evenly to the plane; Liang Yu et al. [4] studied the accessibility of Beijing-Tianjin-Hebei network by using spatial syntactic model and summed up the trend of divergence between Beijing-Tianjin-Hebei and Beijing-Tianjin-Hebei development axes. Meiqing Zhang [5] used the revised spatial interaction model to analyze the rail network accessibility and its spatial pattern, construct a coupling coordination model to evaluate the coordinated relationship between the accessibility and economic linkage in Jing-Jin-Ji metropolitan area. Keone Kelobonye [6] employs a simple but powerful, policy friendly "accessible-opportunities" approach to examine the relative accessibility and spatial equity of five key urban land uses in Perth, Australia. The current research focuses on the traffic accessibility of urban agglomeration and the impact of traffic on urban development trend, and has achieved certain results. At the same time, many scholars have discussed the degree of correlation between traffic integration and urban agglomeration integration through the theoretical level, and lack of calculation method to analyze the traffic integration level through the data model.

Taking the road network of Changsha-Zhuzhou-Xiangtan City Group core regional as the research object, using gravity metric model and road weighted density model to construct accessibility model, this paper analyzes the spatial characteristics of accessibility in the core area of Changsha-Zhuzhou-Xiangtan City Group [7]. A new calculation method of traffic integration level is proposed by comprehensive considering the traffic network connection mode and the gravity model. The correlation between urban agglomeration integration and traffic integration level is studied by principal component analysis method. The degree of traffic development of Changsha-Zhuzhou-Xiangtan City Group is analyzed and the present situation of urban agglomeration integration is demonstrated [8]. The conclusion is great significance to the planning and layout of the traffic network of Changsha-Zhuzhou-Xiangtan City Group. 


\section{Research Methods}

\subsection{Gravity Model}

The prototype of gravity model is the universal gravity model proposed by physicist Newton [9]. Through the distribution of different geographical entities in the region and their own attributes to measure the accessibility of cities, better reflect the degree of inter-city ties, is the most commonly used model of the degree of economic ties between cities. The equation is:

$$
R_{i j}=\frac{\sqrt{P_{i} V_{i}} \sqrt{P_{j} V_{j}}}{D_{i j}^{2}}
$$

where $R_{i j}$ is the traffic network connection degree between cities $i$ and $j, P_{i}$ and $P_{j}$ are the regional population indexes of the two cities, and are usually expressed by the total population, $V_{i}$ and $V_{j}$ are the economic indexes of the two cities, and are usually used to express the GDP of the region, and $D_{i j}^{2}$ represents the distance of the cities $i$ to $j$.

\subsection{Comprehensive Distance Model}

The comprehensive distance between cities can consider the transportation mode, time cost and transportation cost of the two cities at the same time. It is a more comprehensive index than the comprehensive index, and can well reflect the advantages and disadvantages of the traffic accessibility between the two cities [10]. The equation is:

$$
D_{i j}^{2}=\sum_{m=1}^{n} c_{i j-m} t_{i j-m} p_{i j-m}
$$

where $D_{i j}^{2}$ represents the comprehensive distance of cities $i$ to $j$, and $c_{i j-m}$ selects the weight of the traffic mode $m$ between cities $i$ to $j ; t_{i j-m}$ is the time cost when the transportation mode $m$ is selected between cities $i$ to $j ; p_{i j-m}$ is the traffic cost when traffic mode $m$ is selected between cities $i$ to $j$.

\subsection{Road Weighted Density Model}

Road density refers to the ratio of the weighted length of different grades of roads to the area of the region, and is a commonly used index to evaluate the traffic situation [11]. The equation is:

$$
P_{i}=\sum_{a=1}^{b} \frac{L_{i-a} \rho_{a}}{A_{i}}, i \in(1,2,3, \cdots, n)
$$

where $P_{i}$ is the road network density $\left(\mathrm{km} / \mathrm{km}^{2}\right)$ of region $i$, and $L_{i-a}$ is the road length of type a of region $i, \rho_{a}$ is the weight of type a road and $A_{i}$ is the land area of region $i$.

Usually, the greater the density of the regional network, the more developed the traffic and the higher the degree of accessibility. But if the density is too high, it will lead to low utilization rate of roads, unreasonable urban land use and ex- 
cessive investment in urban traffic construction. Conversely, the density of road network is too small, the more backward the traffic, the lower the accessibility, which will easily lead to traffic congestion and affect the travel efficiency of residents [12].

\subsection{New Measurement Method of Transportation Integration Level}

Transportation integration refers to the unified management of transportation and planning among several cities with geographical proximity, under the impetus of social and economic development, to break through the administrative boundaries of cities, to establish cross-regional transportation infrastructure, and promote the development of regional economy [13]. With the help of gravity measurement model, diffusion potential, comprehensive scale and other theories to study the degree of economic connection between cities, be directed against of the characteristics of traffic network and the overall impact of traffic on the integration of urban agglomeration. Based on the calculation model of the degree of economic connection which the formula (1), a new model of transportation integration level is proposed. The equation is:

$$
\begin{gathered}
Y=\sum T_{i j} \\
T_{i j}=\frac{\sqrt{L_{i} / S_{i}} \sqrt{L_{j} / S_{j}}}{D_{i j}^{2}}
\end{gathered}
$$

where $Y$ is the level of traffic integration; $T_{i j}$ is the traffic network link between city $i$ and $j L_{p} L_{j}$ is the road index of two cities, usually represented by the general road length in urban administrative division; $S_{p} S_{j}$ is the area size index of two cities, usually expressed in administrative planning area; $D_{i j}^{2}$ represents the comprehensive distance of the city $i$ and $j$.

\section{Results and Discussion}

\subsection{Research Area}

The research area of this paper is the core area of Changsha-Zhuzhou-Xiangtan City Group. According to the planning of Changsha-Zhuzhou-Xiangtan City Group, the " $3+5$ " urban circle is put forward. Its core areas are Changsha, Zhuzhou, Xiangtan, and its subordinate cities and counties: Changsha County, Wangcheng County, Liuyang City, Ningxiang City, Xiangtan County, Shaoshan City, Xiangxiang County, Liling City, Zhuzhou County, You County, Chaling County, Yanling County (Figure 1).

\subsection{Data Acquisition and Processing}

The data of this paper mainly include Changsha-Zhuzhou-Xiangtan City Group economic development data and road network data. The road network data is mainly derived from the download data of OpenStreetMap. 


\section{Administrative map of Changsha-Zhuzhou- Xiangtan City Group}

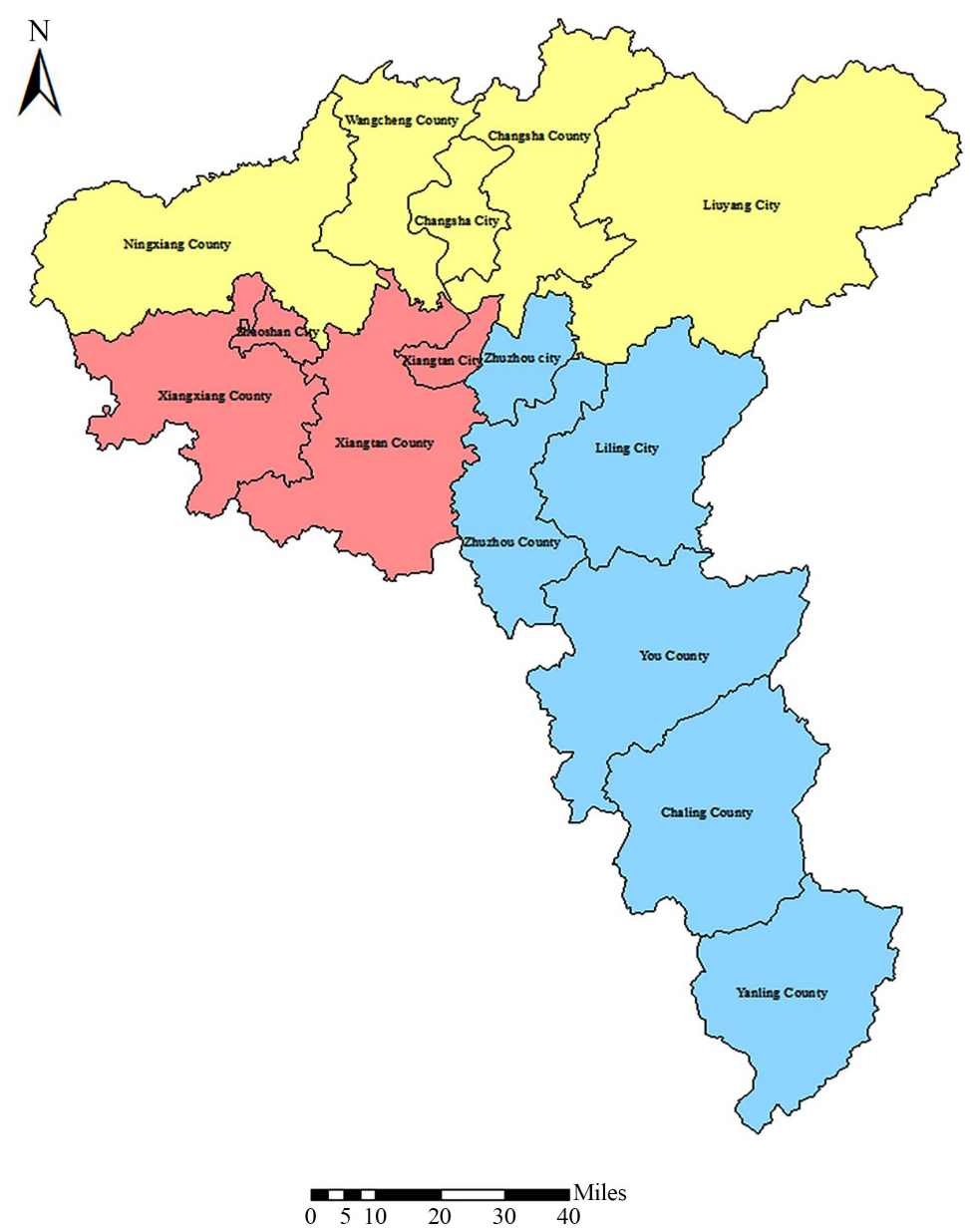

Figure 1. Administrative map of Changsha-Zhuzhou-Xiangtan City Group.

\subsubsection{Basic Data}

Based on the electronic map of Changsha-Zhuzhou-Xiangtan City Group, the road network geo-spatial database of Changsha-Zhuzhou-Xiangtan City Group was established by means of ArcGIS software [14] (Figure 2). The total road mileage is $6333.59 \mathrm{~km}$, of which the high-speed railway is $336.69 \mathrm{~km}$, the railway is $774.39 \mathrm{~km}$, the expressway is $984.30 \mathrm{~km}$, the national highway is $1067.30 \mathrm{~km}$, the provincial road is $1625.90 \mathrm{~km}$, the expressway is $1545.01 \mathrm{~km}$ (Table 1).

\subsubsection{Road Weighted Allocation}

In the traffic network of Changsha-Zhuzhou-Tan city group, railway transportation and road traffic are mainly included. Which railway including high-speed railway and ordinary railway. Road traffic includes expressway, national highway, provincial and urban road. According to the grade of different roads, the difference between the influence ability of manpower and logistics circulation among cities is analyzed, combined with score by experts, the weight of road is 
given to the road by comprehensive evaluation method, and the weight value of different grade roads is obtained [15] (Table 2).

\subsection{Analysis of Results}

\subsubsection{Traffic Accessibility Analysis of Urban Agglomeration}

In the traffic network of Changsha-Zhuzhou-Tan city group, the interpolation map of comprehensive distance accessibility presents a "point-face" shape (Figure 3). As

Table 1. Odometer of different grades of Changsha-Zhuzhou-Xiangtan City Group.

\begin{tabular}{|c|c|c|c|c|c|c|c|}
\hline Realm name & $\begin{array}{l}\text { Area } \\
\left(\mathrm{km}^{2}\right)\end{array}$ & $\begin{array}{l}\text { High-speed } \\
\text { railway } \\
(\mathrm{km})\end{array}$ & $\begin{array}{c}\text { Railway } \\
(\mathrm{km})\end{array}$ & $\begin{array}{c}\text { Expressway } \\
(\mathrm{km})\end{array}$ & $\begin{array}{c}\text { National } \\
\text { road } \\
(\mathrm{km})\end{array}$ & $\begin{array}{c}\text { Provincial } \\
\text { road } \\
(\mathrm{km})\end{array}$ & $\begin{array}{c}\text { Urban } \\
\text { expressway } \\
(\mathrm{km})\end{array}$ \\
\hline $\begin{array}{c}\text { Changsha } \\
\text { City }\end{array}$ & 576.89 & 56.38 & 62.07 & 129.59 & 103.89 & 235.03 & 542.11 \\
\hline $\begin{array}{c}\text { Changsha } \\
\text { County }\end{array}$ & 1973.45 & 66.19 & 18.30 & 149.52 & 124.47 & 105.31 & 218.75 \\
\hline $\begin{array}{c}\text { Wangcheng } \\
\text { County }\end{array}$ & 1354.96 & 0.00 & 45.36 & 99.46 & 74.21 & 47.26 & 253.04 \\
\hline $\begin{array}{c}\text { Liuyang } \\
\text { City }\end{array}$ & 4998.17 & 0.00 & 68.20 & 13.74 & 188.23 & 164.87 & 43.96 \\
\hline $\begin{array}{c}\text { Ningxiang } \\
\text { County }\end{array}$ & 2916.54 & 0.00 & 24.71 & 38.84 & 41.82 & 209.46 & 41.97 \\
\hline $\begin{array}{c}\text { Xiangtan } \\
\text { City }\end{array}$ & 268.95 & 0.00 & 52.64 & 84.29 & 45.44 & 60.32 & 90.43 \\
\hline $\begin{array}{c}\text { Xiangtan } \\
\text { County }\end{array}$ & 2528.61 & 36.58 & 51.70 & 97.65 & 75.06 & 71.66 & 56.43 \\
\hline $\begin{array}{c}\text { Xiangxiang } \\
\text { City }\end{array}$ & 2002.17 & 32.44 & 65.92 & 100.53 & 0.00 & 168.35 & 6.39 \\
\hline $\begin{array}{c}\text { Shaoshan } \\
\text { City }\end{array}$ & 210.56 & 18.97 & 13.81 & 0.00 & 0.00 & 26.06 & 19.92 \\
\hline $\begin{array}{c}\text { Zhuzhou } \\
\text { City }\end{array}$ & 553.12 & 41.15 & 95.28 & 87.13 & 44.33 & 138.23 & 148.40 \\
\hline $\begin{array}{c}\text { Zhuzhou } \\
\text { County }\end{array}$ & 1364.68 & 49.68 & 68.73 & 109.12 & 20.73 & 109.74 & 68.95 \\
\hline $\begin{array}{l}\text { Youxian } \\
\text { County }\end{array}$ & 2661.86 & 0.00 & 66.62 & 0.00 & 67.34 & 137.53 & 10.13 \\
\hline $\begin{array}{l}\text { Liling } \\
\text { city }\end{array}$ & 2157.52 & 35.30 & 99.04 & 74.43 & 109.13 & 43.56 & 44.53 \\
\hline $\begin{array}{l}\text { Yanling } \\
\text { County }\end{array}$ & 2023.42 & 0.00 & 0.00 & 0.00 & 97.03 & 33.77 & 0.00 \\
\hline $\begin{array}{l}\text { Chaling } \\
\text { County }\end{array}$ & 2491.24 & 0.00 & 42.02 & 0.00 & 75.61 & 74.77 & 0.00 \\
\hline
\end{tabular}

Table 2. Weight by different classes of road.

\begin{tabular}{ccccccc}
\hline $\begin{array}{c}\text { Road } \\
\text { type }\end{array}$ & $\begin{array}{c}\text { High-speed } \\
\text { railway }\end{array}$ & Railway & Expressway & $\begin{array}{c}\text { National } \\
\text { road }\end{array}$ & $\begin{array}{c}\text { Provincial } \\
\text { road }\end{array}$ & $\begin{array}{c}\text { Urban } \\
\text { expressway }\end{array}$ \\
\hline Weight & 0.3 & 0.2 & 0.2 & 0.15 & 0.1 & 0.05 \\
\hline
\end{tabular}




\section{Traffic distribution map of Changsha-Zhuzhou Xiangtan City Group}

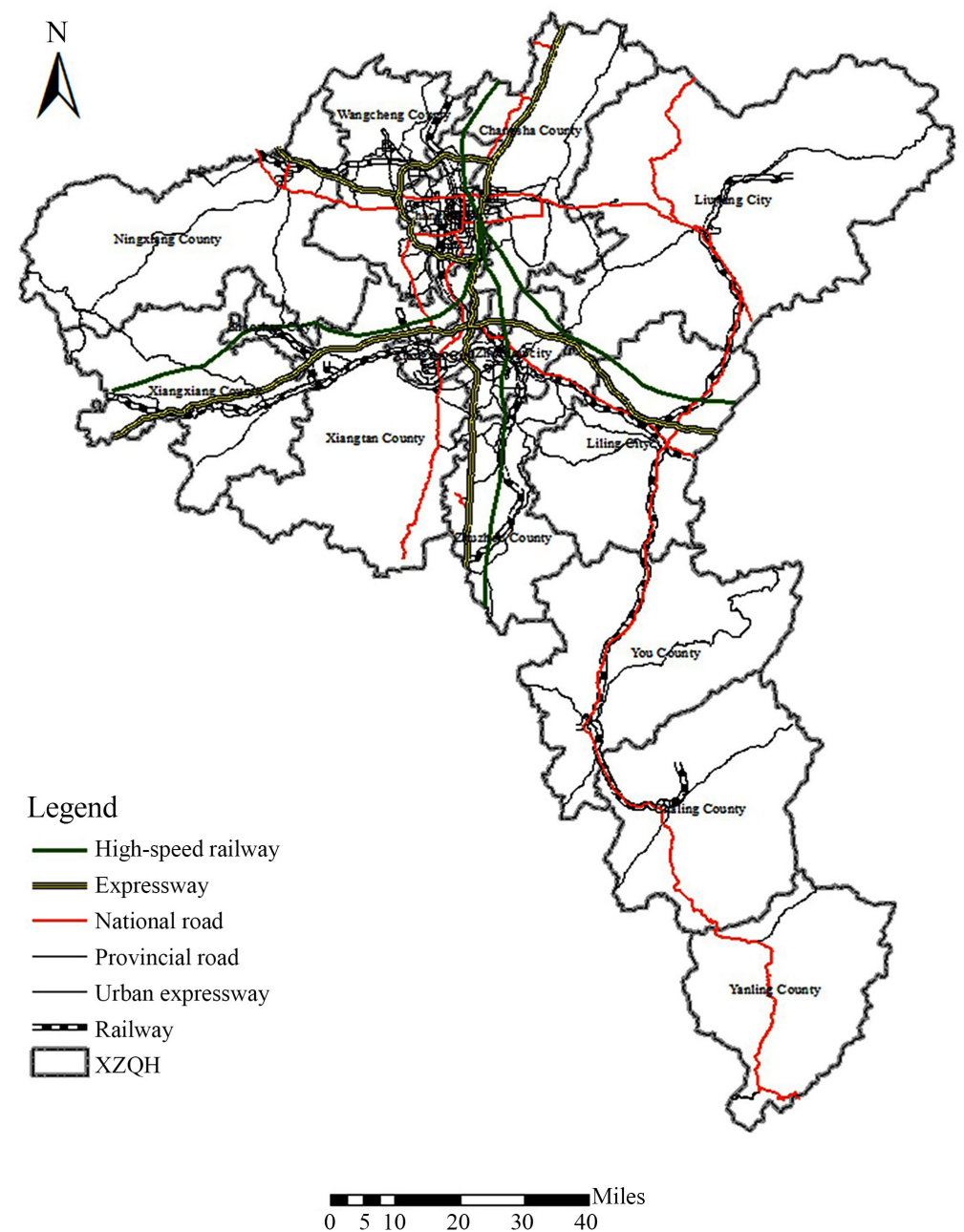

Figure 2. Traffic distribution map of Changsha-Zhuzhou-Xiangtan City Group.

a central area, Changsha is also the core area of regional transportation. In terms of space distance, Changsha City is close to becoming the regional center of mass and it is relatively close to the surrounding cities [16]. In terms of transportation mode, high-speed rail, expressway, national highway and other options are provided. In terms of time distance, because of the proximity, there are many options. Time also showed an advantage. At the same time, Changsha County, Zhuzhou City and Xiangtan City, which are close to Changsha City, also have a higher accessibility, while Ningxiang, Liuyang, Youxian, Chaling and Yanling are relatively low in traffic accessibility.

\subsubsection{Road Weighted Density Analysis of Urban Agglomeration}

In the traffic network of Changzhou-Zhuzhou-Xiangtan urban agglomeration, the area with the highest road weighted density is Changsha, Xiangtan and Zhuzhou, which appear to form vertical zonal distribution as a whole (Figure 4). 


\section{Comprehensive distance accessibility of Changsha- Zhuzhou-Xiangtan City Group}

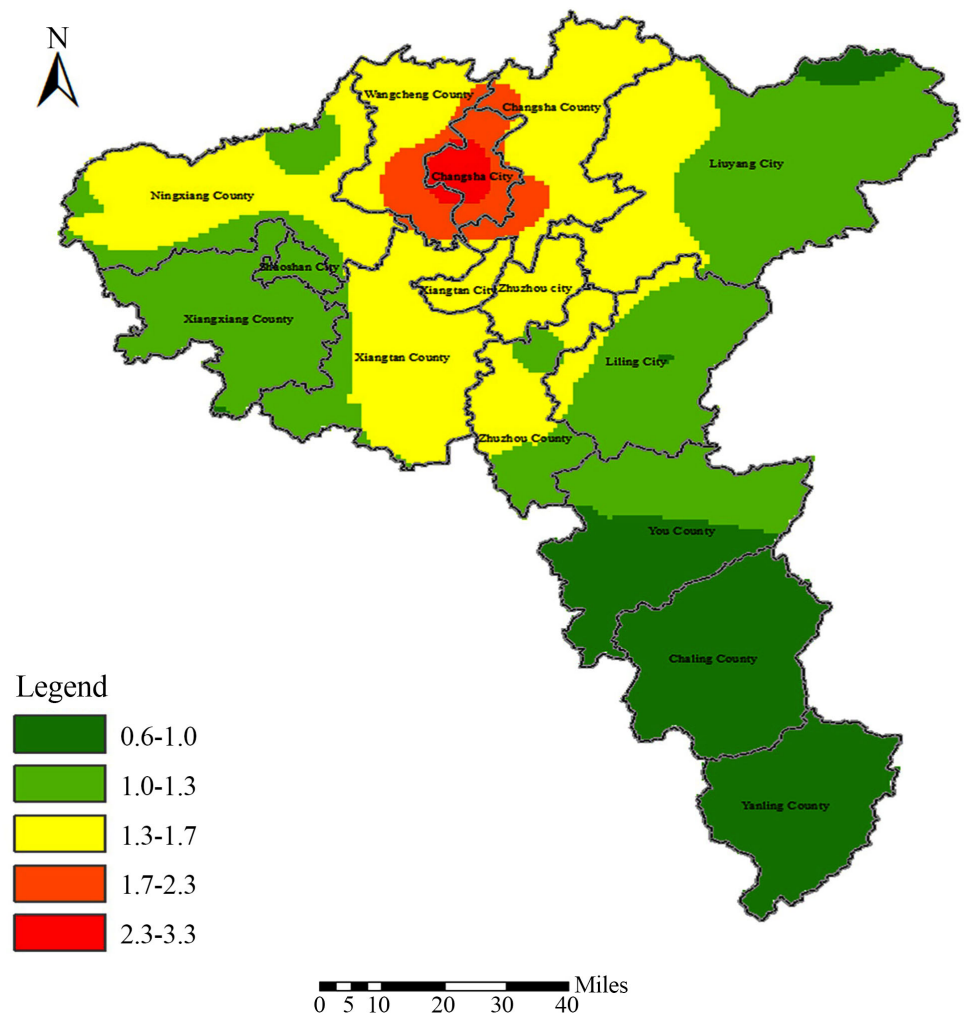

Figure 3. Interpolation diagram of comprehensive distance accessibility of Changsha-Zhuzhou-Xiangtan City Group.

In the area with the highest weighted density, there are main roads such as Jingzhu Expressway, Shanghai-Kunming Expressway, G107, G319, G320 and so on. At the same time, there are many expressways between cities. Because of the high speed railway transportation superiority, the weighted proportion is bigger, in the Changsha City, Xiangtan County, Zhuzhou City, Shaoshan City, Liling City which has the high speed railway passes, road weight density is also relatively high. In Youxian County, Chaling County and Yanling County, the weighted density of the road network is relatively low because of the relative deviation of the location and the lack of major traffic roads (Table 3).

\subsubsection{Analysis on the Degree of Transportation Integration in Urban Agglomeration}

In the development of urban agglomeration to a certain level, transportation network and the total economic volume of urban agglomeration, population are closely related [17]. In this paper, formulas (4)-(5) are used to calculate the measures of traffic integration level. Based on the population GDP and road network data of Changsha City and Changsha Zhuzhou-Xiangtan City Group, the degree of economic and traffic connection between Changsha City and surrounding urban areas is calculated. With the help of SPSS software, the correla- 
tion analysis of the calculation results of the degree of economic connection and the degree of traffic connection is carried out (Table 4). The results show that the correlation between Changsha City and the surrounding urban area is 0.871 . The correlation between Changsha City and the surrounding urban area is very high. It reflects the direct effect of traffic network on economy in urban agglomeration.

\section{Conclusions}

With the help of gravity measurement model, traffic comprehensive distance

\section{Road weight density distribution of Changsha- Zhuzhou-Xiangtan City Group}

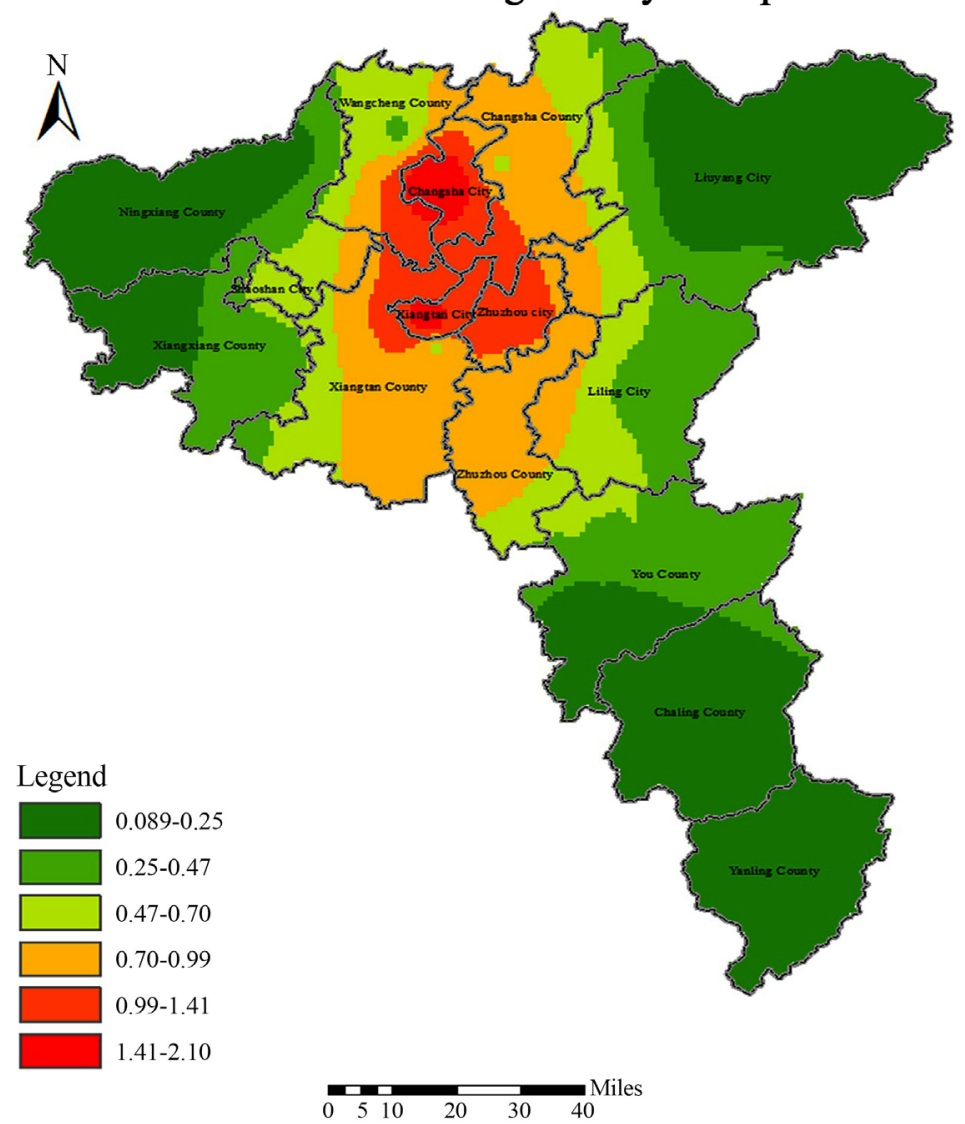

Figure 4. Road weighted density distribution of Changsha-Zhuzhou-Xiangtan City Group.

Table 3. Road network weighted density of everyone city.

\begin{tabular}{cccccccccc}
\hline $\begin{array}{c}\text { Realm } \\
\text { name }\end{array}$ & \multicolumn{2}{c}{ Changsha } & Changsha & Wangcheng & Liuyang & Ningxiang & Xiangtan & Xiangtan & Xiang- \\
County & County & City & County & City & County & xiang City \\
\hline $\begin{array}{c}\text { Weighted } \\
\text { density }\end{array}$ & 0.2105 & 0.0474 & 0.0424 & 0.0127 & 0.0144 & 0.1664 & 0.0246 & 0.0301 \\
$\begin{array}{c}\text { Realm } \\
\text { name }\end{array}$ & $\begin{array}{c}\text { Shaoshan } \\
\text { City }\end{array}$ & $\begin{array}{c}\text { Zhuzhou } \\
\text { City }\end{array}$ & $\begin{array}{c}\text { Zhuzhou } \\
\text { County }\end{array}$ & $\begin{array}{c}\text { Liling } \\
\text { city }\end{array}$ & $\begin{array}{c}\text { Youxian } \\
\text { County }\end{array}$ & $\begin{array}{c}\text { Yanling } \\
\text { County }\end{array}$ & Chaling & County & \\
$\begin{array}{c}\text { Weighted } \\
\text { density }\end{array}$ & 0.0572 & 0.1387 & 0.0498 & 0.0316 & 0.0142 & 0.0089 & 0.0109 & \\
\hline
\end{tabular}


Table 4. Correlation analysis of economic connection degree and traffic network connection degree between Changsha and surrounding cities.

\begin{tabular}{ccc}
\hline Realm name & Economic connection degree & Traffic connection degree \\
\hline Changsha County & 280 & 337 \\
Liuyang City & 57 & 72 \\
Ningxiang County & 105 & 234 \\
Xiangtan City & 126 & 290 \\
Zhuzhou City & 175 & 325 \\
Liling City & 34 & 80 \\
Wangcheng County & 125 & 265 \\
Xiangxiang City & 40 & 118 \\
Correlation coefficent & & 0.871 \\
\hline
\end{tabular}

model, road weighted density model and traffic integration model, the traffic accessibility and traffic integration level of Changsha-Zhuzhou-Xiangtan City Group are comprehensively studied. It puts forward a new method to measure the level of traffic integration. The road network data and socio-economic data of Chang-Zhuzhou-Xiangtan City Group are used to verify the method, and the traffic accessibility and economic connection degree among cities in the region are comprehensively evaluated. The results show that:

1) The most accessible area in Changsha-Zhuzhou-Xiangtan City Group is the core area of Changsha City, Xiangtan City and Zhuzhou City is the second, the regional economic development is good, the traffic network density is high. But the distant area is due to natural conditions and economic development, etc. The accessibility is very low, such as Yanling County, Chaling County.

2) In the calculation of the comprehensive distance of traffic and the weighted density of roads, the city is taken as the basic unit, and the influence factors such as the main intersections between cities are not taken into account. At the same time, the ability to influence the inter-city connection is much lower than that of high-speed railway, which is not taken into account in this paper.

3) According to the relationship between traffic integration and urban agglomeration integration, a metrological algorithm for the degree of intercity traffic network connection is put forward. Through the analysis of the correlation between the degree of transportation network connection and the degree of economic connection, the result reflects the influence of traffic on urban agglomeration economy.

4) More influence factors will be taken into account to measure the degree of traffic connection in future studies to improve the accuracy of the analysis results.

\section{Acknowledgements}

This paper was jointly funded by the National Key R\&D Projects (No. 
2017YFB0503802, 2018YFB0505401).

\section{Conflicts of Interest}

The authors declare no conflicts of interest regarding the publication of this paper.

\section{References}

[1] Hansen, W.J. (1959) How Accessibility Shapes Land Use. Journal of the American Planning Association, 25, 73-76. https://doi.org/10.1080/01944365908978307

[2] Rode, P. (2017) Accessibility in Cities: Transport and Urban Form. LSE Cities, London School of Economics \& Political Science, London.

[3] Li, T., Wen, X.B., et al. (2017) Study on the Impact of the Spatial Pattern of Tourist Attractions in the Pearl River Delta with Intercity Rail Construction. Geomatics \& Spatial Information Technology, 40, 15-19.

[4] Liang, Y., Zheng, X.Q. and Bai, S.J. (2016) The Accessibility Research of Jing-Jin-Ji Road Network Using Space Syntax Model. Bulletin of Surveying and Mapping, No. 10, 101-105.

[5] Zhang, M. and Hu, D. (2016) The Coupling-Coordination Relationship between Accessibility and Economic Linkage in Jing-Jin-Ji Metropolitan Area. 2016 International Conference on Logistics, Informatics and Service Sciences (LISS), Sydney, $1-6$.

[6] Kelobonye, K., McCarney, G. Xia, J.H., Hasan Swapan, M.S., Mao, F. and Zhou, H. (2019) Relative Accessibility Analysis for Key Land Uses: A Spatial Equity Perspective. Journal of Transport Geography, 75, 82-93. https://doi.org/10.1016/j.jtrangeo.2019.01.015

[7] Meng, D., Li, Y., et al. (2019) Analysis of Regional Traffic Dominance Based on Different Indicators-Taking Shandong Province as an Example. IOP Conference Series. Earth and Environmental Science, 381, Article ID: 012063. https://doi.org/10.1088/1755-1315/381/1/012063

[8] Michael, J., Steven, F. and Tijs, N. (2015) Spatiotemporal Accessibility to Supermarkets Using Public Transit: An Interaction Potential Approach in Cincinnati, Ohio. Journal of Transport Geography, 42, 72-83.

https://doi.org/10.1016/j.jtrangeo.2014.11.004

[9] Wu, X.C. (2002) Principles and Methods of Geographical Information Systems. Publish House of Electronics Industry, Beijing.

[10] Zhang, Y., Xu, S., Kang, F. and Yin, S. (2019) Improvement of Regional Spatial Interaction Based on Spatial Traffic System Accessibility: A Case Study in Shandong Province, China. In: Li, D. and Zhao, C., Eds., Computer and Computing Technologies in Agriculture XI. CCTA 2017. IFIP Advances in Information and Communication Technology, Volume 546, Springer, Cham.

[11] Li, T., Wu, J., Sun, H., et al. (2016) Integrated Co-Evolution Model of Land Use and Traffic Network Design. Networks and Spatial Economics, 16, 579.

[12] Liu, R., Hu, W.P., et al. (2011) The Road Network Evolution of Guangzhou-Foshan Metropolitan Area Based on Kernel Density Estimation. Scientia Geographica Sinica, 31, 81-86.

[13] Yin, J.B., Huang, X.Y., et al. (2016) The Effect of Transport Accessibility on Urban Growth Convergence in China: A Spatial Econometric Analysis. Acta Geographica Sinica, 10, 1767-1782. 
[14] Zhong, S.Y., Yang, X. and Chen, R. (2016) The Accessibility Measurement of Hierarchy Public Service Facilities Based on Multi-Mode Network Dataset and the TwoStep 2SFCA: A Case Study of Beijing's Medical Facilities. Geographic Research, 35, 731-744.

[15] Hawthorne, T.L. and Meip, K. (2012) Using GIS and Perceived Distance to Understand the Unequal Geographies of Healthcare in Lower-Income Urban Neighborhoods. The Geographical Journal, 178, 18-30.

[16] Weiss, D., Nelson, A., Gibson, H., et al. (2018) A Global Map of Travel Time to Cities to Assess Inequalities in Accessibility in 2015. Nature, 553, 333-336.

[17] Moyano, A., Moya-Gómez, B. and Gutiérrez, J. (2018) Access and Egress Times to High-Speed Rail Stations: A Spatiotemporal Accessibility Analysis. Journal of Transport Geography, 73, 84-93. https://doi.org/10.1016/j.jtrangeo.2018.10.010 